\title{
Taurine attenuates apoptosis in primary liver cells isolated from Atlantic salmon (Salmo salar)
}

\author{
Marit Espe* and Elisabeth Holen \\ National Institute of Nutrition and Seafood Research (NIFES), PO Box 2029 Nordnes, N-5817 Bergen, Norway
}

(Submitted 27 April 2012 - Final revision received 6 September 2012 - Accepted 7 September 2012 - First published online 27 November 2012)

\begin{abstract}
One of the many functions of taurine is to protect cells against oxidation, by protecting mitochondrial integrity and respiration. Taurine metabolism has attracted much attention in fish nutrition due to the fact that as plant ingredients replace fishmeal, dietary taurine has declined. As the endogenous synthesis of taurine might be too low to protect cells against oxidative stress and apoptosis, the present study aimed to test whether taurine may protect liver cells from apoptosis. Liver cells isolated from Atlantic salmon (Salmo salar) were grown in media supplemented with a physiological concentration of taurine (25 (SE 0.5$)$ mM) or without any taurine supplementation (14 (SE 3) $\mu \mathrm{M})$ for $3 \mathrm{~d}$. To increase oxidation in the mitochondria and maximise any cellular response of taurine supplementation, $100 \mu \mathrm{M}-\mathrm{CdCl}_{2}$ was added or not added to the cells at day 3. At day 4, cells were harvested and assessed for viability. As expected, the addition of $\mathrm{CdCl}_{2}$ decreased cell viability without showing any interaction with taurine supplementation. Cells grown in the taurine-supplemented media had lower protein abundance of active caspase-3. In addition, the protein abundance of phosphorylated mitogen-activating phosphokinase (P-p63, P-p42/44 and P-p38) as well as cytochrome P450 were reduced when taurine was added to the media. Cells grown without taurine supplementation had a more condensed chromatin and more smeared DNA, also pointing to a higher apoptosis in these cells. In conclusion, taurine attenuated apoptosis in primary liver cells isolated from Atlantic salmon, and as such, taurine may be conditionally indispensable in Atlantic salmon.
\end{abstract}

Key words: Taurine: Primary liver cells: Mitochondria: Apoptosis: Atlantic salmon

Sulphur amino acids act as nutrient signals controlling oxidative status through their metabolism and synthesis of glutathione and taurine acting as intracellular antioxidants ${ }^{(1-4)}$. Inflammation and oxidation are important factors that regulate proinflammatory signalling pathways ${ }^{(5)}$. The literature supports the notion that dietary antioxidants are useful radioprotectors and play important roles in preventing many diseases such as cancer, atherosclerosis, stroke, neurodegeneration and diabetes in different cell models ${ }^{(6,7-12)}$. The $\beta$-amino acid taurine is present in millimolar concentrations in most animal tissues $^{(1,13)}$ including Atlantic salmon (Salmo salar) ${ }^{(14,15)}$. Taurine may protect against oxidative stress, neurodegenerative diseases and atherosclerosis, and plays important roles in several physiological processes such as osmoregulation, immunomodulation and bile acid formation ${ }^{(16,17)}$. Atlantic salmon produce taurine from sulphur amino acids through trans-sulfuration ${ }^{(14)}$ and, in addition, taurine is delivered through dietary fishmeal. As marine ingredients are exchanged with plant ingredients, not containing any taurine, a deficiency of taurine may arise using such diets. Deficiencies in taurine may result in increased mitochondrial oxidation and may possibly be linked to the increased lipid accretion reported when dietary taurine is low in rodents ${ }^{(18,19)}$ and in Atlantic salmon ${ }^{(20,21)}$.

Severe taurine limitation, as observed in taurine transporter knockout mice, may trigger liver disease and apoptosis ${ }^{(22,23)}$. Apoptosis is the cellular process in which the cell dies in a controlled fashion either spontaneously or in response to environmental toxicants ${ }^{(24,25)}$. Mitochondria are the cell's sensor to oxidative stress by losing membrane potential, releasing cytochrome $c$ and other pro-apoptotic factors into the cytosol. Mitochondrial permeability is regulated by the $\mathrm{Bcl}-2$ family of proteins. Bcl-2 family proteins regulate apoptosis by controlling mitochondrial permeability and cytochrome $c$ release. $\mathrm{Bcl}-2$ and $\mathrm{Bcl}-\mathrm{xL}$ inhibit cytochrome $c$ release, thus being anti-apoptotic, while other $\mathrm{Bcl}-2$ family protein members such as Bad, Bid, Bax and Bim are located in the cytosol but may translocate to the mitochondria following death signals and thus promote cytochrome $c$ release ${ }^{(26)}$. The mitogen-activating phosphokinase (MAPK) signalling pathway is highly conserved through evolution and transduces a variety of extracellular stress signals such as temperature, irradiation, osmotic shock, cytokines, hormones and inflammation ${ }^{(27)}$.

Abbreviations: MAPK, mitogen-activating phosphokinase; MTT, 3-(4,5-dimethylthizol-2yl)-2,5-diphenyltetrazolium bromide; P450, cytochrome P450; SAH, $S$-adenosylhomocysteine; SAM, S-adenosylmethionine.

*Corresponding author: Dr M. Espe, email marit.espe@nifes.no 
When cells become apoptotic, the abundance of phosphorylated MAPK such as p63, p42/44 and p38 has been reported to increase in cells isolated from rodents ${ }^{(25,28-30)}$. Cytochrome P450 ( $\mathrm{P} 450$ ) enzymes are the most important phase I biotransformation enzymes of environmental chemicals ${ }^{(31,32)}$. These enzymes are involved in the detoxification of liver cells in fish ${ }^{(33)}$. As with the abundance of phosphorylated MAPK, $\mathrm{P} 450$ also has been found to increase in apoptotic cells ${ }^{(24,29)}$.

It is known that $\mathrm{Cd}$ intoxication increases the expression of stress genes ${ }^{(34)}$, and modulates antioxidant enzymes ${ }^{(35,36)}$. Prophylactic treatments with taurine in rodent models reduce lipid peroxidation following treatments with pro-oxidants such as meththiocarb $^{(37)}, \mathrm{Cd}^{(24)}$ and Fe overload ${ }^{(38)}$. Hepatotoxicants have been reported to reduce $S$-adenosylmethionine (SAM) and affect the trans-sulfuration pathway ${ }^{(39)}$. Transmethylation of homocysteine to methionine by the enzyme betainehomocysteine methyltransferase requires methyl groups from betaine ${ }^{(40)}$. Animals have the capacity of endogenous synthesis of both choline and betaine when intake of these metabolites is low. Choline is synthesised from ethanolamine through three successive transmethylation reactions consuming $\mathrm{SAM}^{(41-43)}$, and choline can be metabolised to betaine within the mitochondrion ${ }^{(44)}$. Glutathione is an important detoxifying molecule for reactive oxygen species and other reactive metabolites acting as a free radical scavenger, and SAM is the primary precursor for glutathione; thus, the depletion of cellular SAM has been associated with liver toxicity $^{(45)}$. As the endogenous synthesis of taurine might be too low to protect the cells against oxidative stress and apoptosis, the present study aimed to assess whether taurine supplementation could improve cell viability and methylation capacity (i.e. the SAM:S-adenosylhomocysteine (SAH) ratio) in primary liver cells isolated from Atlantic salmon. To maximise any protective effects of taurine administration ${ }^{(24)}$, cells were also stressed with $\mathrm{CdCl}_{2}$ for $24 \mathrm{~h}$ and compared with unstressed cells.

\section{Materials and methods}

\section{Isolation of liver cells}

Liver cells were isolated from four Atlantic salmon (S. salar) with an average body weight of 1443 (SE 71) g, two males and two females. The fish were anaesthetised by metocaine
(MS222, 5-8g/l) and the liver was perfused with a 0.09 M-HEPES buffer containing $1.4 \mathrm{M}-\mathrm{NaCl}, 0.067 \mathrm{M}-\mathrm{KCl}$ and $0.03 \mathrm{M}$-EDTA, $\mathrm{pH} 7 \cdot 4$, at a flow of $4 \mathrm{ml} / \mathrm{min}$ until free of blood. Thereafter, the liver was digested with collagenase $(0 \cdot 1 \% \mathrm{col}-$ lagenase type IV was dissolved in the 0.9M-HEPES buffer as used for perfusion). The isolated cells were harvested in $10 \mathrm{ml}$ of $10 \%$ PBS buffer (0.002 $\mathrm{M}-\mathrm{KH}_{2} \mathrm{PO}_{4}, 0.02 \mathrm{M}-\mathrm{Na}_{2} \mathrm{HPO}_{4}$, $0 \cdot 03 \mathrm{M}-\mathrm{KCl}$ and $0 \cdot 14 \mathrm{M}-\mathrm{NaCl}, \mathrm{pH} 7 \cdot 4)$, filtered (100 $\mu \mathrm{m}$ filter) and washed twice in the PBS buffer, resuspended in the respective test media before the viability of the isolated cells was assessed. All centrifugations were done by $50 \boldsymbol{g}$ for $5 \mathrm{~min}$. The viability of the cells was examined with the Trypan Blue exclusion test in accordance with the protocol supplied by the manufacturer (Lonzo; Medprobe). The viability of the isolated primary liver cells was above 90 (range 90.8-94.4)\%. The isolations of the cells were done with sterile equipment and buffers. The experimental protocol was approved by the Norwegian Board of Experiments with Living Animals.

\section{In vitro study}

Cells were grown in Leibovitz's-15 medium (catalogue no. L1518; Sigma-Aldrich) supplemented with $1 \%$ of 2 mm-gluta$\max 100 \times($ Gibco Life Technologies), $1 \%$ antibiotics (penicillin, $10000 \mathrm{U} / \mathrm{ml}$, streptomycin, $10000 \mu \mathrm{g} / \mathrm{ml}$ and amphotericin $\mathrm{B}, 25 \mu \mathrm{g} / \mathrm{ml}$; Lonzo Medprobe) and $10 \%$ fetal calf serum (Sigma-Aldrich) to which taurine was added or not added (Sigma-Aldrich). The mean analysed taurine concentration in Leibovitz's-15 medium not supplemented with taurine was 14 ( $\mathrm{SE} 5) \mu \mathrm{M}$ ( $n$ 4), while the corresponding taurinesupplemented media contained 25 (SE 0.5) mm-taurine close to the physiological concentration in the liver of Atlantic salmon fed adequate methionine and cyst(e)ine (26 mm) calculated from Espe et al. ${ }^{(14)}$. Cells were grown for $3 \mathrm{~d}$ on laminin-coated $\left(1.8 \mu \mathrm{g} / \mathrm{cm}^{2}\right.$; Sigma-Aldrich) flasks and cover slides before the addition of $100 \mu \mathrm{M}-\mathrm{CdCl}_{2}$ (prepared in sterile water as described elsewhere $\left.{ }^{(46)}\right)$ to half of the cells and cells were allowed to grow for $24 \mathrm{~h}$ until harvested at day 4 . Cells were grown at a density of 0.5 mill cells $/ \mathrm{cm}^{2}$ and a temperature of $9 \pm 0.5^{\circ} \mathrm{C}$ in the dark in a normal atmosphere incubator (Sanyo Incubator model MIR-253). The cell study design is illustrated in Fig. 1.

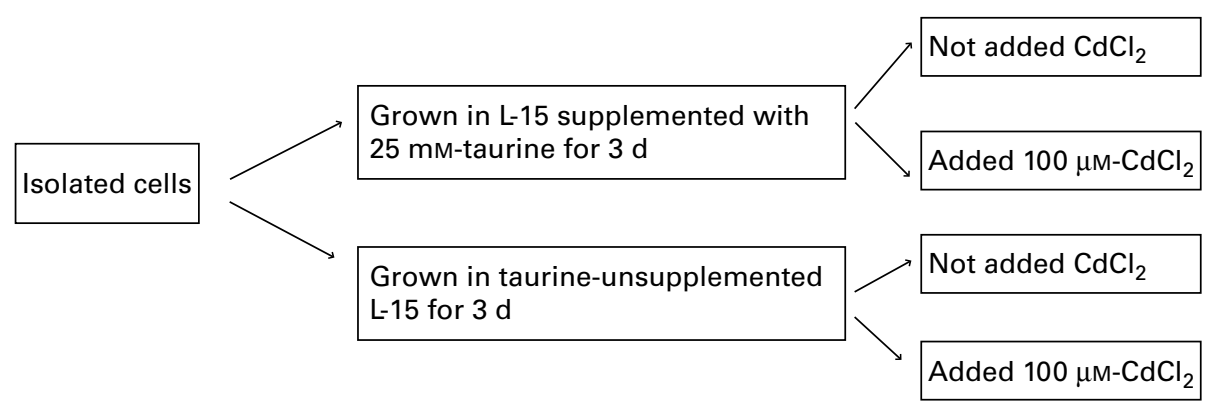

Fig. 1. Schematic illustrating the design of the cell study conducted. Primary liver cells isolated from Atlantic salmon (Salmo salar) were grown in the respective media containing $14 \mu \mathrm{M}$ - or $25 \mathrm{~mm}$-taurine for $3 \mathrm{~d}$ before supplemented or unsupplemented with $100 \mu \mathrm{M}-\mathrm{CdCl}_{2}$. Following $\mathrm{CdCl}_{2}$ supplementation, cells were grown for $24 \mathrm{~h}$ before being harvested for imaging and analyses. Each cell study was repeated with cells isolated from four fish and at each trial, the four treatments were assessed. 


\section{Chemical analyses}

Amino acid composition in deproteinised cells was determined on the Biochrom 20 plus Amino Acid Analyzer (Amersham Pharmacia Biotech) equipped with a lithium column using post-column derivatisation with ninhydrin as described previously ${ }^{(47)}$. Standards for both amino acids and N-metabolites were from Sigma. SAM and SAH were analysed as described in Wang et al. ${ }^{(48)}$. Total homocysteine was determined as described previously ${ }^{(14)}$.

Cells were harvested and washed three times in $10 \mathrm{ml}$ PBS buffer. Thereafter, cells were lysed in $1 \mathrm{ml}$ lysis buffer (50 mm-Tris- $\mathrm{HCl}, \mathrm{pH} 8 \cdot 0,150 \mathrm{~mm}-\mathrm{NaCl}$ and $1 \% \mathrm{NP}-40$ containing protease inhibitor cocktail) on ice for $30 \mathrm{~min}$. The lysed cells were spun at $10000 \mathrm{~g}$ for $15 \mathrm{~min}$ and the supernatant was aliquoted and stored at $-80^{\circ} \mathrm{C}$ until analysed. Betaine and choline were analysed in the lysed supernatants by LC MS/MS (Bevital, www.bevital.no).

\section{Assessment of cell viability}

Viability of the cells was estimated by the In vitro Toxicology assay kit, MTT (3-(4,5-dimethylthizol-2yl)-2,5-diphenyltetrazolium bromide) following the instructions from the supplier using a dual wavelength $(570$ and $690 \mathrm{~nm}$, catalogue no. M5655, M8910; Sigma-Aldrich). The assay is based on the fact that the yellow-coloured MTT will be cleaved by mitochondrial dehydrogenases present in viable cells yielding a purple colour, while dead cells will remain yellow. Thus, the higher the absorbance, the less is the viability. Change in absorbance was calculated relative to the absorbance of dead cells, which was set equal to 100 .

In addition, viable or dead cells were assessed by the Viability/Cytotoxicity Assay Kit for Animal Live and Dead Cells (catalogue no. 30002; Biotum, Inc.). The EthD-III component binds to nucleic acids and produces a red fluorescence in dead cells. EthD-III is excluded by intact membranes and live cells are stained green by calcein AM. The assay followed the procedure given by the supplier. Cells were investigated for fluorescence using a Confocal Microscope (Leica TCS SP2 AOBS; Molecular Imagine Center, University of Bergen). Results are given as calcein AM-positive cells as a percentage of total cells present on each image.

\section{Transmission electron microscopy}

Cell cultures were prepared for transmission electron microscopy (Jeol JEM-1230; Molecular Imaging Center, University of Bergen). Electron microscopy was used to evaluate any structural changes in the primary liver cells following the treatments.

\section{DNA fragmentation}

Monolayer cells (without the supernatants) were lysed in liquid $\mathrm{N}_{2}$ before purified for total DNA using the DNeasy ${ }^{\circledR}$ Blood \& Tissue Kit (catalogue no. 69504), following the supplier's instructions (Qiagen), and frozen at $-80^{\circ} \mathrm{C}$ until analysed. Samples were dissolved in loading buffer (1:6, v/v, 0.25\% bromophenol blue, 0.25\% xylene cyanol and $15 \%$ Ficoll in distilled water). DNA fragmentation was analysed on $1 \%$ agarose gels, stained with GelRed Nucleic Acid Stain (Biotium) and run with $1 \times$ Tris-acetate-EDTA buffer at $70 \mathrm{~V}$ for $1 \mathrm{~h}$. Molecular weight ladder (2log DNA ladder 0·1-10 kb, catalogue no. NEBFN3200; BioLab, Inc.) was used. DNA fragmentation was visualised using a Chemi Chemiluminescence Image Capture (Syngene)

\section{Western blot}

Cells (22.5 million) were harvested and washed three times in $10 \mathrm{ml}$ PBS buffer. Thereafter, cells were lysed in $1 \mathrm{ml}$ lysis buffer (50 mm-Tris- $\mathrm{HCl}, \mathrm{pH} 8 \cdot 0,150 \mathrm{~mm}-\mathrm{NaCl}$ and $1 \% \mathrm{NP}-40$ containing a protease inhibitor cocktail tablet, 11697498001; Roche) on ice for $30 \mathrm{~min}$. The lysed cells were centrifuged at $10000 \mathrm{~g}$ for $15 \mathrm{~min}$ and the supernatants were stored at $-80^{\circ} \mathrm{C}$ until analysed. Samples were prepared for SDS gel by mixing equal amounts of sample and Laemmli sample buffer (catalogue no. 161-0710; BioRad) before heating the samples for $5 \mathrm{~min}$ at $95^{\circ} \mathrm{C}$. Samples and molecular weight marker (Precision Plus Protein ${ }^{\mathrm{TM}}$ WesternC $^{\mathrm{TM}}$ Standards, catalogue no. 161-0376; BioRad) were loaded into precast 10\% SDS gels (catalogue no. 456-1033; BioRad) using a BioRad Mini Protean ${ }^{\circledR}$ Cell according to the manufacturer's instructions. Proteins were blotted onto a polyvinylidene difluouride membrane (catalogue no. 162-0176; BioRad) for $1 \mathrm{~h}$ at $100 \mathrm{~V}$, using the BioRad Criterion ${ }^{\mathrm{TM}}$ Blotter System. The membranes were washed five times with $20 \mathrm{ml}$ TPBS buffer (PBS/0.1\% Tween-20), shaking, before blocking for $1 \mathrm{~h}$ with blocking buffer (catalogue no. RPN2135; GE Healthcare) or 5\% bovine serum albumin/TPBS, shaking. Primary antibodies were added directly into the blocking solution (1:1000) and incubated overnight at $4^{\circ} \mathrm{C}$, shaking. The following primary rabbit antibodies from Cell Signaling (MedProbe) were as follows: $\beta$-actin (no. 4967), P-p63 (S160/162, no. 4981), P-p42/44 MAPK (T202/Y204, no. 4370), Bax (no. 2772), Bcl-2 (50E3, no. 2870), P-p38 (Thr180/Tyr182, no. 9215), while active caspase-3 (ab13847) and P450 (A1 + A2 cytochrome, no. ab37131) were purchased from AbCam. The membranes were washed as described above. Then, horseradish peroxidase-linked secondary anti-rabbit IgG (1:500, no. 7074; Cell Signaling) and Precision Protein ${ }^{\mathrm{TM}}$ StrepTactin-HRP conjugate (catalogue no. 161-0380; BioRad) were added to freshly made blocking buffer (catalogue no. RPN2135; GE Healthcare) and incubated for $2 \mathrm{~h}$, shaking, before washing (six times, $20 \mathrm{ml}$ ) with PBS buffer. The Amersham ECL-Advance ${ }^{\mathrm{TM}}$ Western Blotting detection kit (GE Healthcare, catalogue no. RPN2135) and the Chemi Chemiluminescence Image capture (Syngene) were used to detect the proteins.

\section{Statistical analyses}

Values are reported as means with their standard errors, based on the liver cells isolated from four individual fish $(n 4)$. Results of taurine supplementation were calculated relative to unsupplemented taurine cells and assessed by the 
Mann-Whitney $U$ test. $P$ values less than 0.05 were considered as statistically different. All statistical analyses were performed using the Statistica program (version 9; Statsoft, Inc.).

\section{Results}

Supplementation of taurine to the media improved the viability of the cells (Fig. 2). The addition of $\mathrm{CdCl}_{2}$ strengthened this effect of taurine supplementation on cell survival without showing any interaction between $\mathrm{CdCl}_{2}$

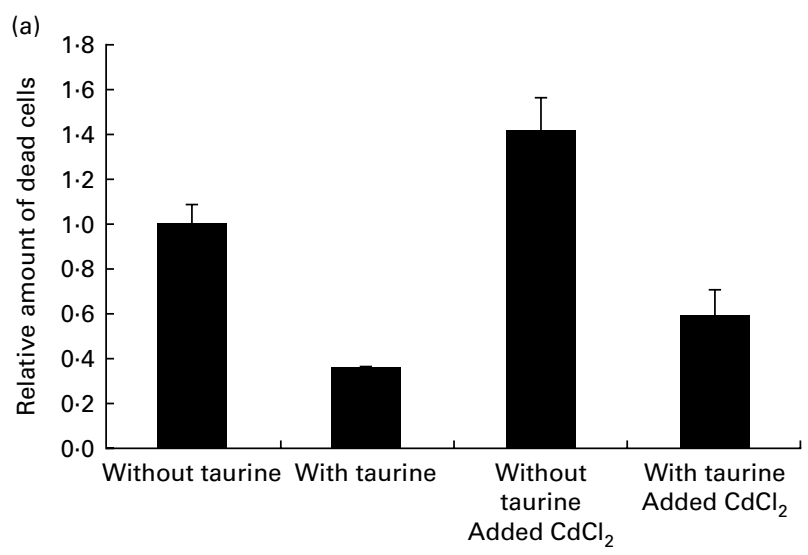

(b)
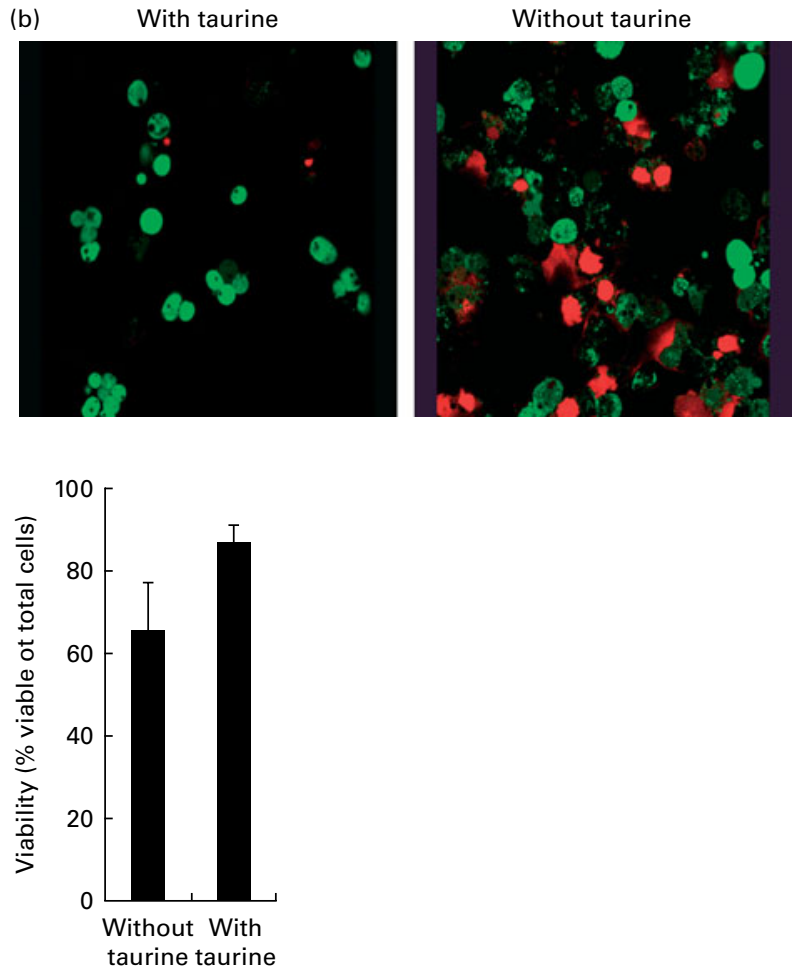

Fig. 2. (a) Taurine supplementation improved viability $(P=0.03)$, while the addition of $\mathrm{CdCl}_{2}$ reduced the viability $(P=0.001)$ and no interaction between taurine and cadmium occurred $(P=0.47)$. Values are means of four repeated treatments, with their standard errors represented by vertical bars. (b) Representative images of cells grown in media supplemented or unsupplemented with taurine stained for viable cells. The red-coloured cells are dead while the green-coloured cells are alive. Cells grown in media supplemented with taurine had better viability ( $P=0.052$; Mann-Whitney $U$ test). and taurine. Cells grown in media without taurine supplementation had a more condensed nucleus, while taurine supplementation seemed to counteract this even in the cells stressed with $\mathrm{CdCl}_{2}$ (Fig. 3(a)). Further, the cells with the more condensed nuclei had more smeared DNA when compared with cells grown in taurine-supplemented media (Fig. 3(b)). As expected, the mitochondrial membranes in cells grown in media supplemented with $\mathrm{CdCl}_{2}$ were more damaged when compared with cells grown in media unsupplemented with $\mathrm{CdCl}_{2}$. However, taurine supplementation by itself did not seem to affect the mitochondrial membranes (Fig. 4).

Taurine supplementation increased the intracellular taurine concentration approximately ten times (from 1093 to $10982 \mu \mathrm{m}$ per million cells), but none of the other free amino acids was affected by taurine supplementation (data not shown). SAM, SAH and total homocysteine were less in cells grown in media supplemented with taurine, but the capacity of methylation analysed as the SAM:SAH ratio was unaffected by taurine supplementation (Fig. 5). Neither choline nor betaine was affected by taurine supplementation (Fig. 5).

As $\mathrm{CdCl}_{2}$ increased the effects of taurine supplementation without showing any interaction with taurine on either the viability or the concentration of metabolites in sulphur amino acid metabolism, the abundance of proteins associated with apoptosis focused on taurine supplementation only (i.e. without taurine was set equal to 100 when independent of $\mathrm{CdCl}_{2}$ administration). The abundance of active cleaved caspase- 3 $(P=0.08)$ was reduced when cells were grown in media supplemented with taurine, while $\operatorname{Bax}(P=0.39)$ and $\mathrm{Bcl}-2$ $(P=1 \cdot 0)$ were unaffected by the treatment (Fig. 6). Furthermore, taurine supplementation decreased the protein abundance of the phosphorylated MAPK (P-p63, P-p42/44, P-p38, $P=0.02, P=0.001$ and $P=0.063$, respectively). Additionally, taurine supplementation reduced the abundance of $\mathrm{P} 450$ $(P=0 \cdot 02$; Fig. 6).

\section{Discussion}

Here, we report that taurine supplementation improves the viability of primary liver cells and reduces the abundance of some proteins associated with apoptosis (caspase-3, MAPK and $\mathrm{P} 450$ ), while others were unaffected by the treatment (Bax and Bcl-2). Risso-de Faverney et al. ${ }^{(49)}$ analysed Bcl-2 family proteins and caspase activation following Cd-induced apoptosis in rainbow trout. Cd increased the abundance of caspase-3, 9 and 8, and increased cytosolic cytochrome $c$ and decreased mitochondrial cytochrome $c$. Similarly, Bax increased in the mitochondria and decreased in the cytosol. In accordance with the results reported by Risso-de Faverney et $a l .{ }^{(49)}$, the present study found that supplementation of $\mathrm{CdCl}_{2}$ reduced viability. The lack of significant changes in Bax and Bcl-2 in the present experiment may be due to the fact that whole cells were analysed and not fractionised into mitochondrial and cytosolic fractions.

Cells grown in the media without taurine supplementation tended to have a higher abundance of active caspase- 3 and 
(a)

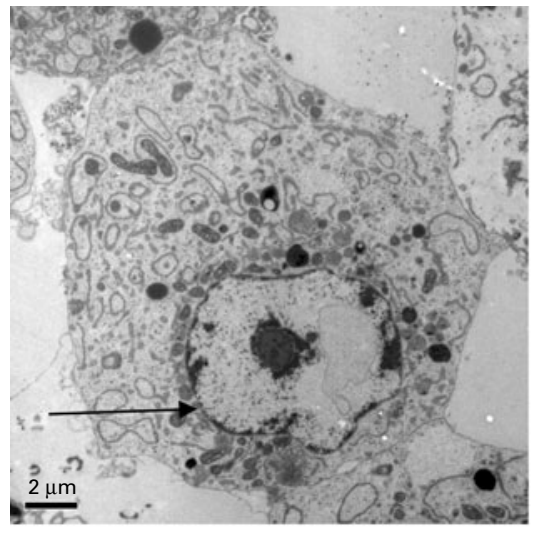

+ Taurine $+\mathrm{CdCl}_{2}$

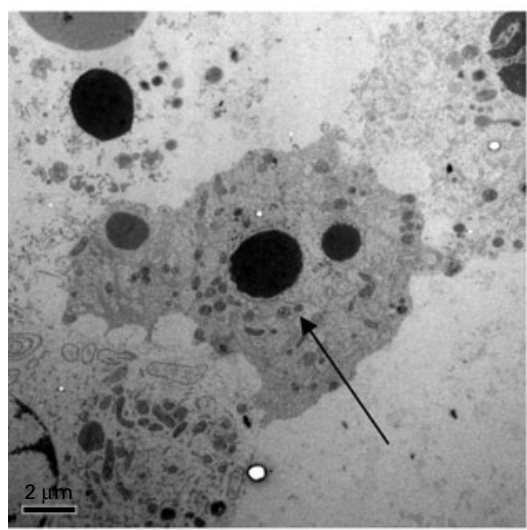

-Taurine $+\mathrm{CdCl}_{2}$

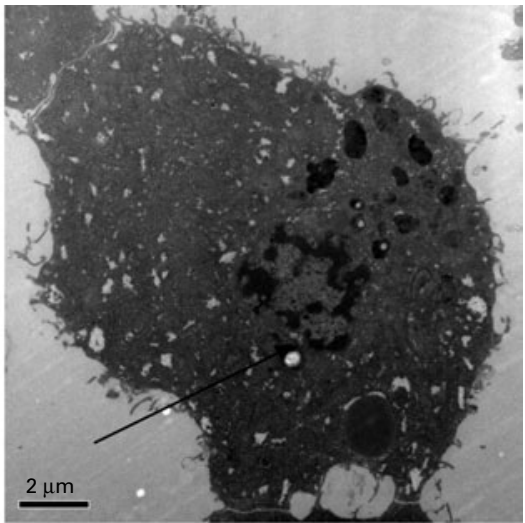

+Taurine- $\mathrm{CdCl}_{2}$

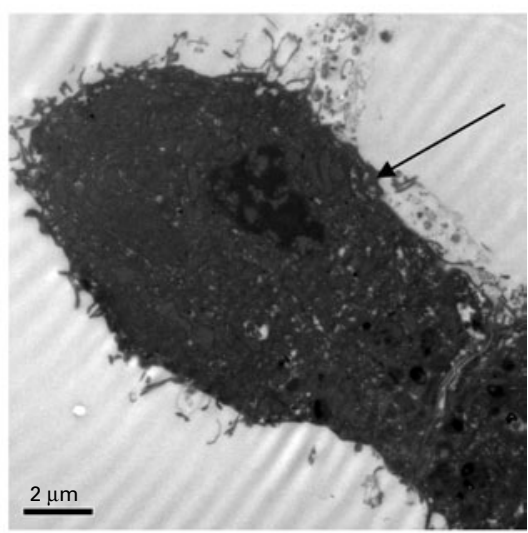

-Taurine- $\mathrm{CdCl}_{2}$

(b)

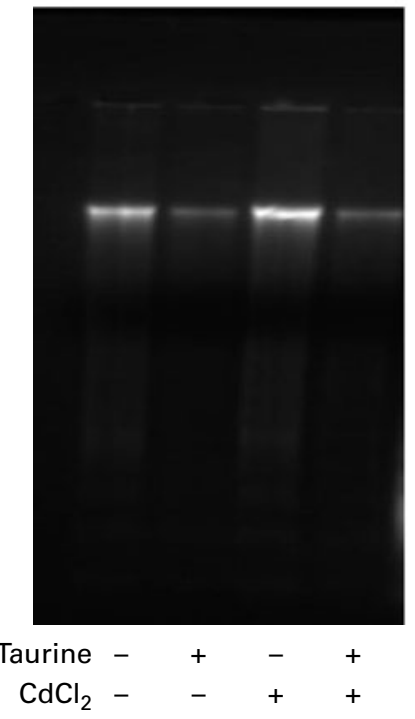

Fig. 3. Representative transmission electron microscopy images of liver cells isolated from Atlantic salmon (Salmo salar) ( $n$ 4) and grown in media supplemented or unsupplemented with taurine and $\mathrm{CdCl}_{2}$. Cells grown in media without taurine supplementation had a more condensed chromatin in the nucleus $(\rightarrow)$ when compared with cells grown in media supplemented with taurine. (a) Addition of $\mathrm{CdCl}_{2}$ to the media increased the abundance of apoptotic cells. When cells were grown without taurine supplementation, a higher DNA smearing occurred. (b) Representative image showing the DNA smearing occurring in cells grown in the four different media. Scale bar $=2 \cdot 0 \mu \mathrm{m}$. 


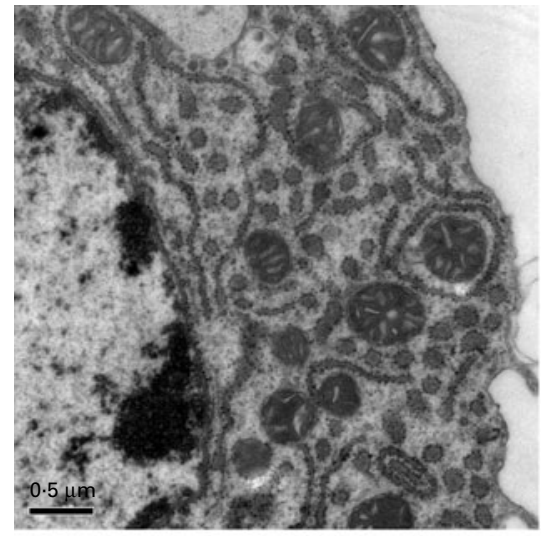

+ Taurine $+\mathrm{CdCl}_{2}$

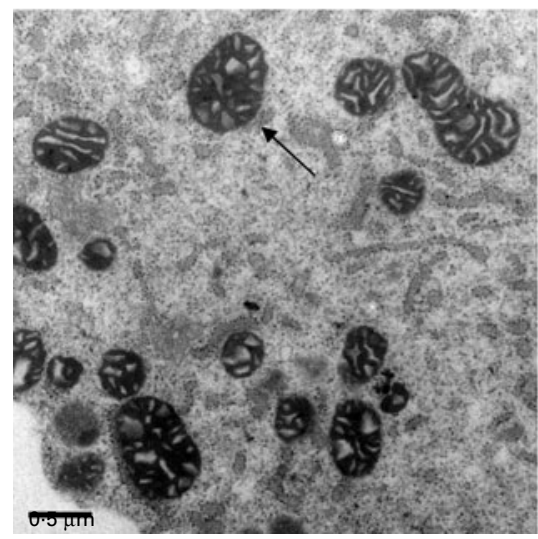

-Taurine+ $\mathrm{CdCl}_{2}$

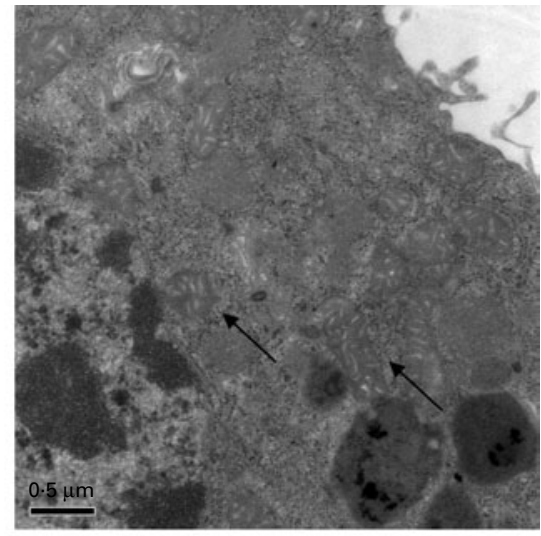

+Taurine- $\mathrm{CdCl}_{2}$

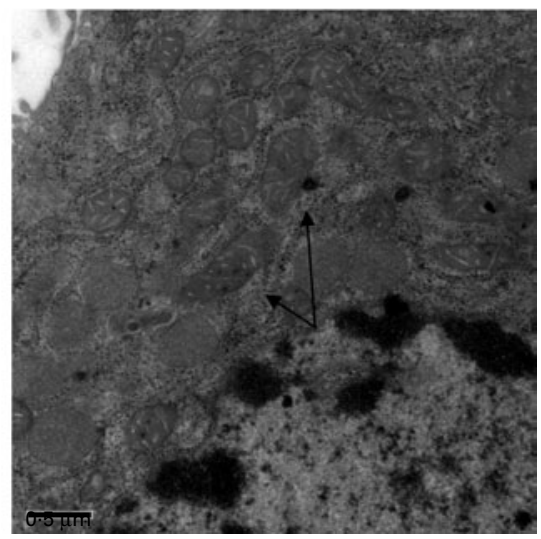

-Taurine- $\mathrm{CdCl}_{2}$

Fig. 4. Representative transmission electron microscopy images of the mitochondrion in liver cells isolated from Atlantic salmon (Salmo salar) $(n 4)$ and grown in media supplemented or unsupplemented with taurine and $\mathrm{CdCl}_{2}$. Cells supplemented with $\mathrm{CdCl}_{2}$ had more swollen mitochondrial membranes $(\rightarrow)$ in line with the lower viability of these cells. Taurine did not seem to affect this swelling $(\rightarrow)$. Scale bar $=0.5 \mu \mathrm{m}$.

showed more DNA fragmentation, indicative of increased apoptosis when compared with cells grown in media supplemented with taurine. Recently, Ghosh et al. ${ }^{(50)}$ reported that active caspase- 3 increased in the heart of transgenic mice with reduced cystathionine $\beta$-synthase activity, the rate-limiting enzyme for trans-sulfuration ${ }^{(51)}$, especially when fed high-fat diets. Also, these mice had less total glutathione and oxidised glutathione in the heart, but no differences in liver glutathione status were observed. We did not analyse glutathione status in the isolated liver cells, but neither catalase nor glutathione peroxidase gene expression was affected (data not shown) by the treatment in the present study. Reduced cystathionine $\beta$-synthase activity not only decreases taurine and glutathione synthesis but may also increase homocysteine $^{(51,52)}$, especially so if betaine is limiting. In the present study, neither betaine nor choline was affected by taurine supplementation, but SAM, SAH and homocysteine all reduced following taurine supplementation. Zulli et al. ${ }^{(6)}$ reported that elevated homocysteine present in rabbits fed an atherogenic diet (high cholesterol and methionine) normalised after taurine administration. However, taurine supplementation failed to improve hyperlipidaemia or the oxidative stress system $^{(6)}$ in rabbits. Thus, the elevated total

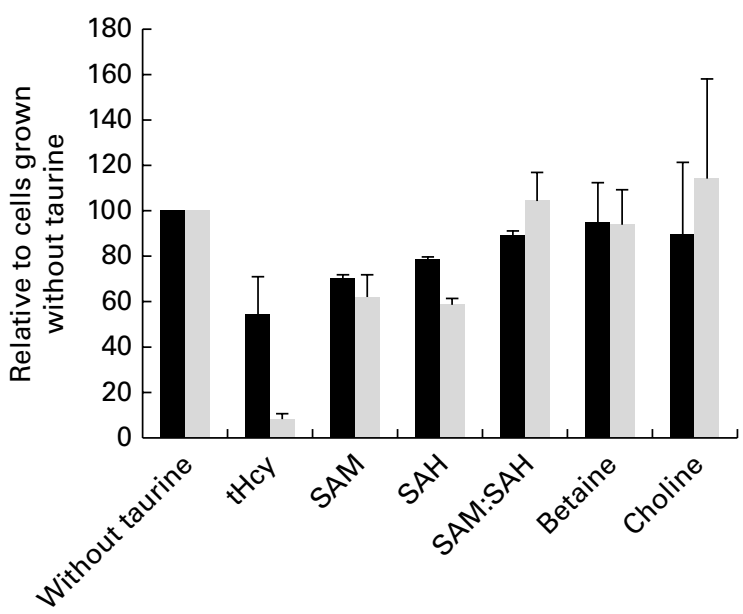

Fig. 5. Metabolites in sulphur amino acid metabolism analysed in free monolayer liver cells isolated from Atlantic salmon (Salmo salar) and grown for $4 \mathrm{~d}$ in media supplemented or unsupplemented with taurine and $\mathrm{CdCl}_{2}$ ( $n$ 4). Values are relative means, as cells grown without taurine supplementation are set equal to 100 , with their standard errors represented by vertical bars. S-adenosylmethionine (SAM), S-adenosyl homocysteine (SAH) and total homocysteine (tHcy) all reduced $(P=0.03,0.03$ and 0.1 , respectively, without $\mathrm{CdCl}_{2}$ and $P=0.02$. 0.02 and 0.03 with $\mathrm{CdCl}_{2}$ supplementation; Mann-Whitney $U$ test) by taurine supplementation. Capacity of methylation (SAM:SAH ratio) and methyl donor concentration (choline and betaine) was

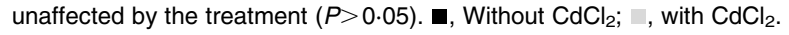



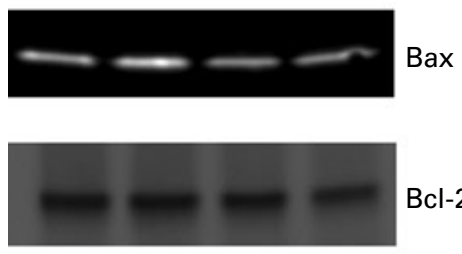

$\mathrm{Bcl}-2$

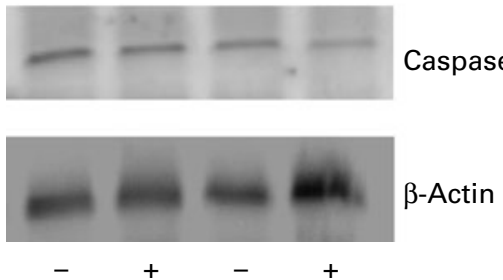

$\begin{array}{llll}- & + & - & +\end{array}$

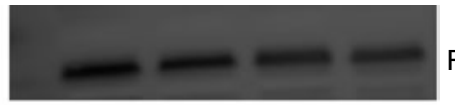

P-p63
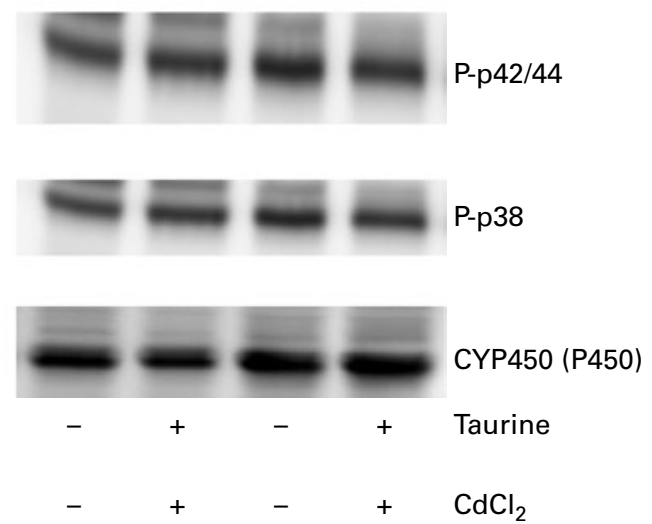

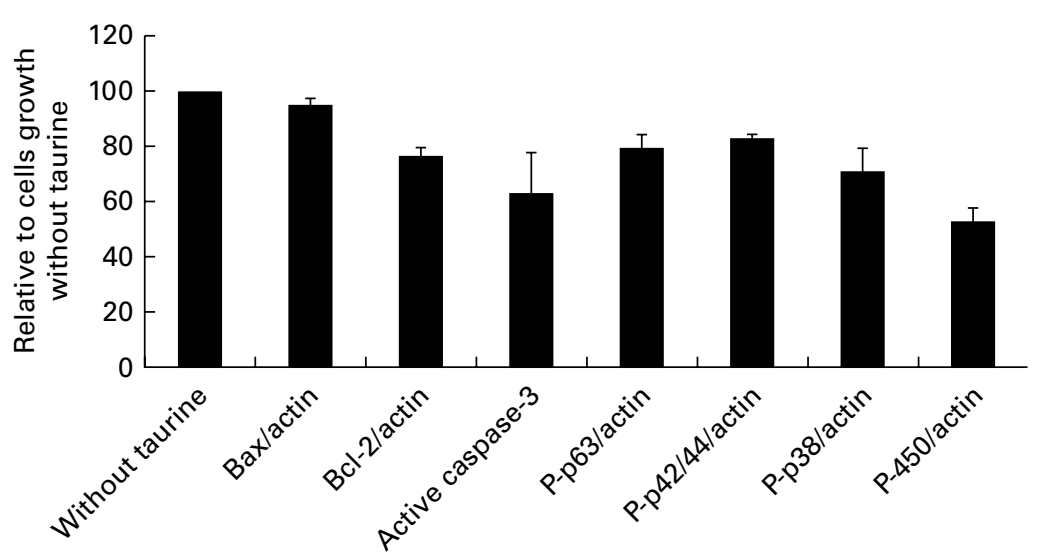

Fig. 6. Abundance of proteins associated with apoptosis as affected by taurine supplementation. Cytochrome $\mathrm{P} 450(P=0.02)$ and the phosphorylated mitogenactivating phosphokinase decreased following taurine supplementation ( $P$-p63 and P-p42/44, $P=0.02$ and $P=0.001$, respectively; Mann-Whitney $U$ test). Also, active caspase-3 abundance and P-p38 decreased when taurine was supplemented, but did not reach significant difference $(P=0.08$ and $P=0.06$, respectively). $\operatorname{Bax}(P=0.39)$ and $\mathrm{Bcl}-2(P=1.0)$ abundance was not affected by taurine supplementation. The proteins present were calculated relative to actin present in each cell lysate, and presented as relative means, as cells grown in media without taurine supplementation is set equal to 100, with their standard errors represented by vertical bars. Representative images from the Western blot of liver cells isolated from four fish $(n 4)$.

homocysteine present in cells grown in media without taurine supplementation also may have contributed to apoptosis in the present study.

Previous studies have shown that phosphorylated MAPK such as P-p63, P-p42/44 and P-p38 increase during apoptosis ${ }^{(25,28-30,53)}$. $\mathrm{P} 450$ has also been reported to increase in apoptotic cells ${ }^{(24,29)}$. The data from the present study thus support increased apoptosis in cells grown in media without taurine supplementation. P-p38 may activate the PPAR $\alpha$ pathway $^{(18,30,53)}$, thus affecting lipid mobilisation. As cells grown in media supplemented with taurine had less P-p38, this suggests the involvement of MAPK signalling pathways for the reduced fat accretion reported when Atlantic salmon were fed diets supplemented with taurine ${ }^{(20,21)}$. Unfortunately, this could not be answered in the present study as the gene expression of PPAR $\alpha$ was unaffected by the treatment (results not shown). However, cytokine activation and lipid mobilisation deserve to be studied in more detail both in vitro and in vivo to unravel cell signalling linking fuel sensing, mobilisation of lipids and MAPK signalling.
Taurine also functions as an osmolyte; therefore supplementation of taurine to the media may have reduced cell shrinkage that acts as a signal for programmed cell death $^{(17,40,54)}$. This may also add to the increased apoptosis observed in the present study.

Several investigators have reported that oxidation is a major determinant for apoptosis and cell dysfunction ${ }^{(24,30,45,55)}$. Even though taurine administration has been reported to prevent apoptosis in experimental inflammatory cell models, taurine treatment alone did not affect either Bax or Bcl-2 expression, oxidative stress or apoptosis in normal rats ${ }^{(55)}$. On the contrary, we here report that taurine administration by itself significantly improved cell viability and reduced the phosphorylated MAPK. As both too little ${ }^{(10)}$ and too much ${ }^{(56)}$ of the sulphur amino acids have been reported to affect the amount of reactive oxygen species and apoptosis, further studies are required to assess the minimum requirement of taurine supplementation to attenuate apoptosis including possible interactions with lipid mobilisation. In doing so, the primary liver cells should be fractionised to enable study of the localisation of apoptotic proteins ${ }^{(49)}$. 


\section{Conclusion}

Taurine may be conditionally indispensable in Atlantic salmon, as it attenuates apoptosis and protects nuclear DNA in primary liver cells isolated from Atlantic salmon. Neither the capacity of methylation nor betaine or choline availability was affected by taurine treatment. More research is needed to determine the minimum concentration of taurine necessary to attenuate apoptosis including cell localisation and mobility of anti-apoptotic and pro-apoptotic proteins.

\section{Acknowledgements}

This study was financed by the Norwegian Ministry of Fisheries and Coastal Affairs. Assistance in the isolation of primary cells by Synnøve Wintertun at the NIFES is highly appreciated. The confocal imaging/electron microscopy was performed at the Molecular Imaging Center (Fuge, Norwegian Research Council), University of Bergen. Both authors contributed equally to the planning and analysis of the cell trials. They participated in the interpretation of the results as well as in the writing of the manuscript. There is no conflict of interest.

\section{References}

1. Schuller-Levis GB \& Park E (2003) Taurine: new implications for an old amino acid. FEMS Microbiol Lett 226, 195-222.

2. Redmond HP, Stapleton PP, Neary P, et al. (1998) Immunonutrition: the role of taurine. Nutrition 14, 559-604.

3. Fang YZ, Yang S \& Wu GY (2002) Free radicals, antioxidants and nutrition. Nutrition 18, 872-879.

4. Oudit Y, Trivieni MG, Khaper N, et al. (2004) Taurine supplementation reduces oxidative stress and improve cardiovascular function in an iron-overloaded murine model. Circulation 109, 1877-1885.

5. Pearson G, Robinson F, Gibson TB, et al. (2001) Mitogenactivated protein (MAP) kinase pathways: regulation and physiological functions. Endocr Rev 22, 153-183.

6. Zulli A, Lau E, Wijaya BPP, et al. (2009) High dietary taurine reduces apoptosis and atherosclerosis in the left main coronary artery association with reduced CCAAT/enhancer binding protein and total plasma homocysteine but not lipidemia. Hypertension 53, 1017-U226.

7. Verzola D, Bertolotto MB, Villaggio B, et al. (2002) Taurine prevents apoptosis induced by high ambient glucose in human tubule renal cells. J Invest Med 50, 443-451.

8. Schaffer S, Solodushko V, Pastukh V, et al. (2003) Possible cause of taurine-deficient cardiomyopathy: potentiation of angiotensin II action. J Cardiovasc Pharm 41, 751-759.

9. Yalcinkaya S, Unlucerci Y, Giris M, et al. (2009) Oxidative and nitrosative stress and apoptosis in the liver of rats fed on high methionine diet: protective effect of taurine. Nutrition 25, 436-444.

10. Ronchi VP, Giudici AM, Mendieta JR, et al. (2010) Oxidative stress in mouse liver caused by dietary amino acid deprivation: protective effects of methionine. J Physiol Biochem 66, $93-103$.

11. Zhao HM, Ruan HH \& Li HT (2011) Progress in the research of GSH in cells. Chinese Sci Bull 56, 3057-3063.

12. Sun M, Gu Y \& Xu C (2011) Protective functions of taurine against experimental stroke through depressing mitochondria-mediated cell death in rat. Amino Acids 40, 1419-1429.
13. Bouckenooghe $\mathrm{T} \&$ Reusens B (2006) Is taurine a functional nutrient? Curr Opin Clin Nutr 9, 728-733.

14. Espe M, Hevrøy EM, Liaset B, et al. (2008) Methionine intake affect hepatic sulphur metabolism in Atlantic salmon, Salmo salar. Aquaculture 274, 132-141.

15. Espe M, Rathore RM, Du Z-Y, et al. (2010) Methionine limitation results in increased hepatic FAS activity, higher liver 18: 1 to 18:0 fatty acid ratio and hepatic TAG accumulation in Atlantic salmon, Salmo salar. Amino Acids 39, 449-460.

16. Della Corte L, Crichton RR, Duburs G, et al. (2002) The use of taurine analogues to investigate taurine functions and their potential therapeutic applications. Amino Acids 23, 367-379.

17. Militante JD \& Lomardini JB (2004) Dietary taurine supplementation: hypolipineric and antiatherogenic effects. Nutr Res 24, 787-801.

18. Tsuboyama-Kasaoka N, Shozawa C, Sano K, et al. (2006) Taurine (2-aminoethanesulfonic acid) deficiency creates a vicious circle promoting obesity. Endocrinology 147, 3276-3284.

19. Liaset B, Madsen L, Qin H, et al. (2009) Fish protein hydrolysate elevates plasma bile acids and reduces visceral adipose tissue mass in rats. BBA - Mol Cell Biol L 1791, $254-262$

20. Espe M, Ruohonen K \& El-Mowafi A (2012) Effect of taurine supplementation on metabolism and body lipid to protein ratio in juvenile Atlantic salmon (Salmo salar). Aquacult Res 43, 349-360.

21. Espe M, Ruohonen K \& El-Mowafi A (2012) Hydrolysed fish protein concentrate (FPC) reduces viscera mass in Atlantic salmon (salmon salar) fed plant-protein-based diets. Aquacult Nutr 18, 599-609.

22. Warskulat U, Borsch E, Reinehr R, et al. (2006) Chronic liver disease is triggered by taurine transporter knockout in the mouse. FASEB J 20, 574-609.

23. Warskulat U, Borsch E, Reinehr R, et al. (2007) Taurine deficiency and apoptosis: findings from the taurine transporter knockout mouse. Arch Biochem Biophys 462, 202-209.

24. Sinha M, Manna P \& Sil PC (2009) Induction of necrosis in cadmium-induced hepatic oxidative stress and its prevention by the prophylactic properties of taurine. J Trace Elem Med Biol 23, 300-313.

25. Das J, Ghosh J, Manna P, et al. (2009) Taurine protects rat testes against $\mathrm{NaAsO}_{2}$-induced oxidative stress and apoptosis via mitochondrial dependent and independent pathways. Toxicol Lett 187, 201-210.

26. Pradelli LA, Bénéteau M \& Ricci J-E (2010) Mitochondrial control of caspase-dependent and independent cell death. Cell Mol Life Sci 67, 4589-1597.

27. Brown MD \& Sacks DB (2009) Protein scaffolds in MAP kinase signaling. Cell Signal 21, 462-469.

28. Xu Y-J, Saini KK, Zhang M, et al. (2006) MAPK activation and apoptotic alterations in hearts subjected to calcium paradox are attenuated by taurine. Cardiovasc Res 72, 163-174.

29. Das J, Ghosh J, Manna P, et al. (2010) Taurine protects acetaminophen-induced oxidative damage in mice kidney through APAP urinary excretion and CYP2E1 inactivation. Toxicology 269, 24-34.

30. Hou X, Shen YH, Li C, et al. (2010) PPAR $\alpha$ agonist fenofibrate protects the kidney from hypertensive injury in spontaneously hypertensive rats via inhibition of oxidative stress and MAPK activity. Biochem Biophys Res Comun 394, 653-659.

31. Fent K (2003) Ecotoxicological problems associated with contaminated sites. Toxicol Lett 140-141, 353-365. 
32. Van der Oost R, Beyer J \& Vermaulen NPE (2003) Fish bioaccumulation and biomarkers in environmental risk assessment: a review. Environ Toxicol Pharmacol 13, 57-149.

33. Søfteland L, Eide I \& Olsvik PA (2009) Factorial design applied for multiple endpoint toxicity evaluation in Atlantic salmon (Salmo salar L.) hepatocytes. Toxicol In Vitro 23, 1455-1463.

34. Wang Z \& Templeton DM (1998) Induction of c-fos protooncogene in mesangial cells by cadmium. J Biol Chem $\mathbf{2 7 3}$, $73-79$.

35. Jay D, Zamorano R, Munoz E, et al. (1991) Study of the interaction of cadmium with membrane-bound succinate dehydrogenase. J Bioenerg Biomembr 23, 381-389.

36. Watjen W, Benters J, Haase $\mathrm{H}$, et al. (2001) $\mathrm{Zn}^{2+}$ and $\mathrm{Cd}^{2+}$ increase the cyclic GMP level in PC12 cells by inhibition of the cyclic nucleotide phosphodiesterase. Toxicology 157, $167-175$

37. Ozden S, Catalgol B, Gezginci-Oktayoglu S, et al. (2009) Methiocarb-induced oxidative damage following subacute exposure and the protective effects of vitamin $\mathrm{E}$ and taurine in rats. Food Chem Toxicol 47, 1676-1684.

38. Devi SL \& Anuradha CV (2010) Mitochondrial damage, cytotoxicity and apoptosis in iron-potentiated alcoholic liver fibrosis: amelioration by taurine. Amino Acids 38, 869-879.

39. Schnackenberg L, Chen M, Sun J, et al. (2009) Evaluations of the trans-sulfuration pathway in multiple liver toxicity studies. Toxicol Appl Pharm 235, 25-32.

40. Li P, Mai K, Trushenski J, et al. (2009) New developments in fish amino acid nutrition: towards functional and environmentally oriented aquafeeds. Amino Acids 37, 43-53.

41. Vance JE \& Vance DE (1985) The role of phosphatidylcholine biosynthesis in the secretion of lipoproteins from hepatocytes. Can J Biochem Cell B 63, 870-881.

42. Vance DE \& Walkey CJ (1998) Roles for the methylation of phosphatidylethanolamine. Curr Opin Lipidol 9, 125-130.

43. Brosnan JT, Jacobs RL, Stead LM, et al. (2004) Methylation demand: a key determinant of homocysteine metabolism. Acta Biochem Pol 51, 405-413.

44. Obeid R \& Herrmann W (2009) Minireview, homocysteine and lipids: $S$-adenosyl methionine as a key intermediate. FEBS Lett 583, 1215-1225.

45. Sun J, Schnackenberg L, Holland RD, et al. (2008) Metabonomic evaluation of urine from rats given acute and chronic doses of acetaminophen using NMR and UPLC/MS. I Chromatogr 871, 328-340.

46. Søfteland L, Holen E \& Olsvik PA (2010) Toxicological application of primary hepatocyte cell cultures of Atlantic cod (Gadus morbua) - effects of BNF, PCDD and Cd. Comp Biochem Physiol C 151, 401-411.

47. Espe M, Lemme A, Petri A, et al. (2006) Can Atlantic salmon grow on diets devoid of fish meal? Aquaculture 255, $255-262$.

48. Wang W, Kramer M, Yang S, et al. (2001) Reversed-phase high-performance liquid chromatography procedure for the simultaneous determination of $S$-adenosyl-L-methionine and $S$-adenosyl-L-homocysteine in mouse liver and the effect of methionine on their concentration. $J$ Chromatogr $B$ 762, 59-65.

49. Risso-de Faverney C, Orsini N, de Sousa G, et al. (2004) Cadmium induced apoptosis through the mitochondrial pathway in rainbow trout hepatocytes: involvement of oxidative stress. Aquat Toxicol 69, 247-258.

50. Ghosh S, Sulistyoningrum DC, Glier MB, et al. (2011) Altered glutathione homeostasis in the hearth augments cardiac lipotoxicity associated with diet-induced obesity in mice. $J$ Biol Chem 286, 42483-42493.

51. Mato JM, Corrales FJ, Lu SC, et al. (2002) S-Adenosylmethionine: a control switch that regulates liver function. FASEB J 16, 15-26.

52. Finkelstein JD (2006) Inborn errors of sulfur-containing amino acid metabolism. $J$ Nutr 136, 1750S-1754S.

53. Meng R, Pei Z, Zhang A, et al. (2011) AMPK activation enhances PPAR $\alpha$ activity to inhibit cardiac hypertrophy via ERK1/2 MAPK signaling pathway. Arch Biochem Biophys 511, $1-7$.

54. Yu XP, Chen K, Wei N, et al. (2007) Dietary taurine reduces retinal damage produced by photochemical stress via antioxidant and anti-apoptotic mechanisms in Sprague-Dawley rats. Br J Nutr 98, 711-719.

55. Giris M, Depooylu B, Dogru-Abbasoglu S, et al. (2008) Effect of taurine on oxidative stress and apoptosis-related protein expression in trinitrobenzene sulphonic acid-induced colitis. Clin Exp Immunol 152, 102-110.

56. Gomez J, Caro P, Sanchez I, et al. (2009) Effect of methionine dietary supplementation on mitochondrial oxygen radical generation and oxidative DNA damage in rat liver and heart. J Bioenerg Biomembr 41, 309-321. 